\title{
Pancreatic cancer-associated gene polymorphisms in a nation-wide cohort of p16-Leiden germline mutation carriers; a case-control study
}

Thomas P Potjer ${ }^{1 *}$, Nienke van der Stoep ${ }^{1}$, Jeanine J Houwing-Duistermaat ${ }^{2}$, Ingrid C A W Konings ${ }^{3}$, Cora M Aalfs ${ }^{4}$, Peter C van den Akker ${ }^{5}$, Margreet G Ausems ${ }^{6}$, Charlotte J Dommering ${ }^{7}$, Lizet E van der Kolk ${ }^{8}$, Merel C Maiburg ${ }^{9}$, Liesbeth Spruijt ${ }^{10}$, Anja Wagner ${ }^{11}$, Hans F A Vasen ${ }^{12}$ and Frederik J Hes ${ }^{1}$

\begin{abstract}
Background: The p16-Leiden founder mutation in the CDKN2A gene is the most common cause of Familial Atypical Multiple Mole Melanoma (FAMMM) syndrome in the Netherlands. Individuals with this mutation are at increased risk for developing melanoma of the skin, as well as pancreatic cancer. However, there is a notable interfamilial variability in the occurrence of pancreatic cancer among p16-Leiden families. We aimed to test whether previously identified genetic risk factors for pancreatic cancer modify the risk for pancreatic cancer in p16-Leiden germline mutation carriers.

Methods: Seven pancreatic cancer-associated SNPs were selected from the literature and were genotyped in a cohort of 185 p16-Leiden germline mutation carriers from 88 families, including 50 cases (median age 55 years) with pancreatic cancer and 135 controls (median age 64 years) without pancreatic cancer. Allelic odds ratios per SNP were calculated.
\end{abstract}

Results: No significant association with pancreatic cancer was found for any of the seven SNPS.

Conclusions: Since genetic modifiers for developing melanoma have already been identified in CDKN2A mutation carriers, this study does not exclude that genetic modifiers do not play a role in the individual pancreatic cancer risk in this cohort of p16-Leiden germline mutation carriers. The search for these modifiers should therefore continue, because they can potentially facilitate more targeted pancreatic surveillance programs.

Keywords: CDKN2A, p16-Leiden, Germline mutation, FAMMM syndrome, Pancreatic cancer, Modifiers, Single nucleotide polymorphisms

\section{Background}

The melanoma gene $C D K N 2 A$ produces two important proteins: $\mathrm{p} 16^{\mathrm{INK} 4 \mathrm{a}}$, which is a cyclin-dependent kinase inhibitor, and $\mathrm{p} 14^{\mathrm{ARF}}$, which binds the p53-stabilizing protein MDM2 [1]. In the Netherlands, a founder mutation in the CDKN2A gene, a 19-base pair deletion called

\footnotetext{
*Correspondence: t.p.potjer@lumc.nl

1 Department of Clinical Genetics, Leiden University Medical Center,

Albinusdreef 2, 2333 ZA Leiden, The Netherlands

Full list of author information is available at the end of the article
}

p16-Leiden (c.225_243del19; RefSeq NM_000077.4), is the most common cause of Familial Atypical Multiple Mole Melanoma (FAMMM) syndrome [2]. In addition to a marked increased risk of developing melanoma of the skin (70\% lifetime risk), these mutation carriers also have a $15-20 \%$ lifetime risk of developing pancreatic cancer with a mean age of 58 years at diagnosis [3]. Interestingly, there is a notable interfamilial variability in the occurrence of pancreatic cancer among p16-Leiden families [3]. Therefore, the p16-Leiden mutation might not be the only genetic risk factor in these individuals causing 
an increased susceptibility for pancreatic cancer. Since pancreatic cancer has a very poor prognosis due to late occurrence of symptoms and therefore late detection, surveillance for pancreatic cancer is currently offered to p16-Leiden germline mutation carriers in a research setting to investigate whether pancreatic cancer, or, even more preferable, high-grade precursor lesions can be detected earlier in a potentially still curable stage [4]. By identifying additional genetic risk factors (genetic modifiers) in these individuals, surveillance could possibly be more individualized.

In recent years, genome-wide association studies (GWAS) have identified several common risk variants associated with pancreatic cancer [5-7]. In this study, we genotyped a selected number of these variants (SNPs) in a unique cohort of p16-Leiden mutation carriers with and without pancreatic cancer. We hypothesized that these SNPs might modify the risk of pancreatic cancer in these p16-Leiden mutation carriers.

\section{Methods}

\section{Study population and DNA sample collection}

For this case-control study, only proven carriers of the p16-Leiden germline mutation were included. From all Dutch p16-Leiden mutation carriers, DNA is stored in the Laboratory for Diagnostic Genome Analysis (LDGA) of the Leiden University Medical Center. All p16-Leiden germline mutation carriers diagnosed at the LDGA between the initiation of CDKN2A gene diagnostics at the LDGA in 1998 and January 1st 2014 were eligible for inclusion. Cases were defined as having been diagnosed with exocrine pancreatic cancer at the time of data collection; controls were at least 55 years old on January 1st 2014 or died beyond that age, and were not diagnosed with pancreatic cancer. Individuals who were younger than 55 years or died before this age were excluded from the control group. Medical records were obtained for each individual from the electronic hospital information system of the medical center where this individual initially received genetic counselling by a clinical geneticist for $C D K N 2 A$ gene diagnostics. Access to these medical records was granted for the (co)authors since they are clinical geneticists working in these medical centers. Additional follow up data was acquired from two ongoing pancreatic surveillance studies (a singlecenter study at Leiden University Medical Center and a multi-center study at Erasmus MC University Medical Center Rotterdam) and from the Netherlands Foundation for the Detection of Hereditary Tumours, a central registration institute for hereditary tumours (FAMMM, amongst others) in the Netherlands. This study was approved by the Ethics Committee of the Leiden University Medical Center, by issuing a declaration of no objection (\#P14.148). This is an assessment of the study protocol on due diligence, that is, if it serves the codes of good practice and good conduct. It is not a formal ethical assessment, because the study does not fall within the scope of the Dutch law for medical research on human subjects; the medical records and the DNA were already available and the involved human subjects were not specifically recruited for the study and were not subjected to any actions. Therefore, no separate ethical assessment or approval was needed for the collection of data in the participating medical centers.

\section{SNP selection and genotyping}

SNPs for genotyping in this cohort were selected from recent GWAS studies with large cohorts of sporadic pancreatic cancer patients [5-7]. Selection was based on significance of association with pancreatic cancer and reported odds ratios, as well as expected allele frequencies. In the first place, SNPs with the largest odds ratios and smallest p-values were selected. Subsequently, only those SNPs with a relatively high minor allele frequency (MAF) were considered for genotyping, because of the limited sample size of the cohort. This would optimize the number of carriers of the minor allele and thereby augment the potential of reaching significance between subgroups. In order to test a relatively wide variety of genes, a maximum of two different SNPs per gene was maintained. All included individuals were genotyped for the selected SNPs using high-resolution DNA melting curve analysis [8]. Melting assays were performed with Lightscanner (Biofire Defense Inc, Salt Lake City, UT, USA).

\section{Statistical analysis}

Given our relatively small sample size, we performed a power calculation with Bonferroni correction for multiple testing prior to the study. Despite a calculated power of approximately $15 \%$, we wanted to pursuit this small but tangible chance of finding a trend of association.

The frequencies of the risk alleles were computed and compared between cases and controls by calculating a SNP-specific allelic odds ratio, including the $95 \%$ confidence interval. Additional p-values were calculated using a basic $\chi^{2}$ test and the Bonferroni correction for multiple testing was applied. Therefore, a $p$ value of less than 0.007 was considered significant. All statistical analyses were performed using SPSS 20.0.0 (IBM Inc, Armonk, NY, USA).

\section{Results}

\section{Patient characteristics (Table 1)}

In total, 422 p16-Leiden germline mutation carriers were eligible for inclusion. Of these, 50 individuals (18 males, 
Table 1 Patient characteristics

\begin{tabular}{lll}
\hline & $\mathbf{p 1 6 - L e i d e n ~ m u t a t i o n ~ c a r r i e r s ~}(\mathbf{N}=\mathbf{1 8 5})$ & \\
\cline { 2 - 3 } & Cases with pancreatic cancer $(\mathbf{N}=\mathbf{5 0})$ & Controls without pancreatic cancer (N = 135) \\
\hline Median age in years (range) & $55(21-76)$ & $64(55-88)$ \\
Gender (m:f) & $18: 32$ & $50: 88$ \\
Medical history of melanoma & $24(48 \%)$ & $74(55 \%)$ \\
Ofwhich multiple & $8 / 24(33 \%)$ & $29 / 74(39 \%)$ \\
\hline
\end{tabular}

$36 \%)$ were diagnosed with pancreatic cancer, with a median age at diagnosis of 55 years (range 21-76 years), and could all be included in the case group. The remaining 372 individuals were not diagnosed with pancreatic cancer, but 237 individuals were excluded from the control group because of not having reached the age of 55 years. The remaining control group consisted of 135 individuals (50 males, 37\%) with a median age of 64 years (range $55-88$ years). Thus, for this study a total of 185 p16-Leiden germline mutation carriers (from 88 families) were included. A considerable number of individuals (98 of 185 [53\%]) developed melanoma, and 37 of 98 individuals with melanoma (38\%) had multiple melanoma. In the case group, 24 of 50 individuals (48\%) had a medical history of melanoma, and in the control group 74 of 135 individuals (55\%) had a medical history of melanoma.

\section{SNP genotyping and association with pancreatic cancer}

A total of seven SNPs in five different genes were selected for genotyping. Table 2 shows the minor allele frequencies of these SNPs in cases and controls, and the calculated association (allelic odds ratio and 95\% confidence interval) with pancreatic cancer in our cohort of p16-Leiden germline mutation carriers. No significant association with pancreatic cancer was found for any of the seven SNPs.

\section{Discussion}

In this case-control study, we analysed seven pancreatic cancer-associated SNPs in a distinctively homogeneous cohort of 185 CDKN2A germline mutation carriers. That is, all cases with $(\mathrm{n}=50)$ and all controls without ( $\mathrm{n}=135)$ pancreatic cancer carry the same p16-Leiden germline mutation. We hypothesized that (a subset of) these SNPs would be associated with an increased pancreatic cancer risk in these individuals, and that genetic modifiers would explain, at least partially, the variability in the occurrence of pancreatic cancer in p16-Leiden families. However, in our cohort, no significant association was found between the occurrence of pancreatic cancer and any of the seven SNPs.
Table 2 Association of seven selected SNPs with pancreatic cancer in this study

\begin{tabular}{|c|c|c|c|c|}
\hline \multirow[t]{2}{*}{ Marker $^{a}$} & \multicolumn{2}{|c|}{$\begin{array}{l}\text { Minor Allele Fre- } \\
\text { quency }\end{array}$} & \multirow[t]{2}{*}{$\begin{array}{l}\text { Allelic OR (95\% } \\
\text { Cl) }\end{array}$} & \multirow[t]{2}{*}{$\begin{array}{l}\text { Sign. } \\
\text { ( } p \text { value) }\end{array}$} \\
\hline & Cases & Controls & & \\
\hline $\begin{array}{l}\text { rs2821367 (T, C) } \\
\text { 1q32.1 } \\
\text { NR5A2 }\end{array}$ & 0.37 & 0.38 & $1.0(0.62-1.62)$ & 1.00 \\
\hline $\begin{array}{l}\text { rs7310409 (G, A) } \\
12 \mathrm{q} 24.31 \\
\text { HNF1A }\end{array}$ & 0.35 & 0.39 & $0.87(0.54-1.41)$ & 0.57 \\
\hline $\begin{array}{l}\text { rs735396 (A, G) } \\
12 \mathrm{q} 23.31 \\
\text { HNF1A }\end{array}$ & 0.33 & 0.36 & $0.90(0.55-1.47)$ & 0.67 \\
\hline $\begin{array}{l}\text { rs1805100 (G, A) } \\
8 q 21.11 \\
\text { HNF4G }\end{array}$ & 0.49 & 0.56 & $0.76(0.48-1.21)$ & 0.24 \\
\hline $\begin{array}{l}\text { rs505922 (T, C) } \\
9 \text { q34.2 } \\
\text { ABO }\end{array}$ & 0.30 & 0.33 & $0.87(0.53-1.44)$ & 0.59 \\
\hline $\begin{array}{l}\text { rs657152 }(G, T) \\
9 q 34.2 \\
A B O\end{array}$ & 0.30 & 0.37 & $0.73(0.44-1.20)$ & 0.22 \\
\hline $\begin{array}{l}\text { rs172310 (C, A) } \\
\text { 7q36.3 } \\
\text { SHH }\end{array}$ & 0.43 & 0.39 & $1.18(0.74-1.89)$ & 0.49 \\
\hline
\end{tabular}

a SNP reference (major/minor allele), chromosome location, gene.

Currently, research on genetic modifiers in CDKN2A mutation carriers is mainly focused on identifying low-risk variants that influence melanoma risk $[9,10]$. To date, the MC1R gene, which is known to have a role in the skin pigmentation process, is the most important modifier gene identified so far $[11,12]$. Penetrance of $C D K N 2 A$ mutations regarding melanoma risk is thus proven to be subject to low-risk genetic variants in other genes. Because of these encouraging results from previous studies, it can be expected that genetic variants could also be identified in CDKN2A mutation carriers which influence pancreatic cancer risk. It is however unlikely that these variants will be the same as those which influence melanoma risk, as Wu and colleagues demonstrated [13]. Other genetic variants should thus be considered when studying the risk of 
pancreatic cancer in $C D K N 2 A$ mutation carriers. Yang et al. [14] made a first attempt at this by sequencing the $P A L B 2$ gene in a small cohort of $C D K N 2 A$ mutation carrying families with pancreatic cancer. The $P A L B 2$ gene (OMIM \#610355) is one of the relatively few known high risk pancreatic cancer susceptibility genes associated with familial pancreatic cancer to date [15]. However, no pathogenic mutations were identified in their study and also no association was found between SNPs in the PALB2 gene and the occurrence of pancreatic cancer.

The strength of this study is that our cohort of p16-Leiden mutation carriers is homogeneous regarding the type of mutation, and therefore relatively large in its kind. Yet, in order to study modifier effects in a cohort of individuals with a genetically inherited predisposition to cancer, a large sample size is important [16]. Because the p16-Leiden mutation is a rare mutation, an important limitation of this study is that sample size cannot easily be increased. Therefore, the lower age limit of the control group was set at 55 years (the mean age of pancreatic cancer in the case group). It is possible that individuals in the control group will develop pancreatic cancer in the future and this could have influenced the results. Possibly, recalculations in the future, taking into account new clinical follow-up data of these individuals, could change the results significantly.

For this study, we selected seven promising pancreatic cancer-associated SNPs from the literature, based on reported odds ratios, $\mathrm{p}$-values and reproducibility. The sample size limitation allowed us to test only a restricted number of SNPs and because of the limited sample size we chose for those with a relatively high minor allele frequency. Our selection of seven SNPs is however only a subset of a much larger set of SNPs associated with pancreatic cancer and it is therefore still possible that these other SNPs do play a role in the pancreatic cancer risk in p16-Leiden germline mutation carriers (see [17] for an overview of associated SNPs). It is also possible that other, non-genetic, risk factors play a role in the variable pancreatic cancer phenotype. However, we do not have sufficient data available of these external risk factors in our studied mutation carriers. One of the most important non-genetic risk factors for developing pancreatic cancer is tobacco use, and even in CDKN2A germline mutation carriers it increases the risk for pancreatic cancer significantly $[18,19]$.

\section{Conclusions}

This study aimed at identifying genetic modifiers that influence pancreatic cancer risk in a homogeneous cohort of Dutch p16-Leiden germline mutation carriers. Despite the fact that no significant association could be found for the seven tested pancreatic cancer-associated
SNPs, it is still possible that these or other genetic modifiers play a significant role in the individual pancreatic cancer risk in these individuals. The search for genetic modifiers for pancreatic cancer in p16-Leiden germline mutation carriers should therefore continue.

\section{Abbreviations}

CDKN2A: Cyclin-dependent kinase inhibitor 2A; FAMMM: familial atypical multiple mole melanoma; GWAS: Genome-Wide Association Study; MAF: minor allele frequency; SNP: single nucleotide polymorphism.

\section{Authors' contributions}

TP, NS, JH and FH designed the study. TP conducted experiments, analysed and interpreted data. TP, IK, CA, PA, MA, CD, LK, MM, LS, AW and HV collected data. TP and FH wrote the manuscript. All authors reviewed the manuscript. All authors read and approved the final manuscript.

\section{Author details}

${ }^{1}$ Department of Clinical Genetics, Leiden University Medical Center, Albinusdreef 2, 2333 ZA Leiden, The Netherlands. ${ }^{2}$ Department of Medical Statistics and Bioinformatics, Leiden University Medical Center, Leiden, The Netherlands. ${ }^{3}$ Department of Gastroenterology and Hepatology,Erasmus MC, University Medical Center, Rotterdam, The Netherlands. ${ }^{4}$ Department of Clinical Genetics, Academic Medical Center, Amsterdam, The Netherlands. ${ }^{5}$ Department of Genetics, University of Groningen, University Medical Center Groningen, Groningen, The Netherlands. ${ }^{6}$ Department of Medical Genetics, University Medical Center Utrecht, Utrecht, The Netherlands. ${ }^{7}$ Department of Clinical Genetics and Human Genetics, VU University Medical Center, Amsterdam, The Netherlands. ${ }^{8}$ Department of Clinical Genetics, The Netherlands Cancer Institute, Amsterdam, The Netherlands. ${ }^{9}$ Department of Clinical Genetics, Maastricht University Medical Center, Maastricht, The Netherlands. ${ }^{10}$ Department of Clinical Genetics, Radboud University Medical Centre, Nijmegen, The Netherlands. ${ }^{11}$ Department of Clinical Genetics, Erasmus MC, University Medical Center, Rotterdam, The Netherlands. ${ }^{12}$ The Netherlands Foundation for the Detection of Hereditary Tumours, Leiden, The Netherlands.

\section{Compliance with ethical guidelines}

\section{Competing interests}

The authors declare that they have no competing interests.

Received: 8 April 2015 Accepted: 17 June 2015

Published online: 26 June 2015

\section{References}

1. Robertson KD, Jones PA (1999) Tissue-specific alternative splicing in the human INK4a/ARF cell cycle regulatory locus. Oncogene 18:3810-3820

2. Gruis NA, van der Velden PA, Sandkuijl LA, Prins DE, Weaver-Feldhaus J, Kamb A et al (1995) Homozygotes for CDKN2 (p16) germline mutation in Dutch familial melanoma kindreds. Nat Genet 10:351-353

3. Vasen HF, Gruis NA, Frants RR, van der Velden PA, Hille ET, Bergman W (2000) Risk of developing pancreatic cancer in families with familial atypical multiple mole melanoma associated with a specific 19 deletion of p16 (p16-Leiden). Int J Cancer 87:809-811

4. Vasen HF, Wasser M, van Mil A, Tollenaar RA, Konstantinovski M, Gruis NA et al (2011) Magnetic resonance imaging surveillance detects earlystage pancreatic cancer in carriers of a p16-Leiden mutation. Gastroenterology 140:850-856

5. Amundadottir L, Kraft P, Stolzenberg-Solomon RZ, Fuchs CS, Petersen GM, Arslan AA et al (2009) Genome-wide association study identifies variants in the $\mathrm{ABO}$ locus associated with susceptibility to pancreatic cancer. Nat Genet 41:986-990

6. Petersen GM, Amundadottir L, Fuchs CS, Kraft P, Stolzenberg-Solomon RZ, Jacobs KB et al (2010) A genome-wide association study identifies pancreatic cancer susceptibility loci on chromosomes 13q22.1, 1q32.1 and 5p15.33. Nat Genet 42:224-228 
7. Li D, Duell EJ, Yu K, Risch HA, Olson SH, Kooperberg C et al (2012) Pathway analysis of genome-wide association study data highlights pancreatic development genes as susceptibility factors for pancreatic cancer. Carcinogenesis 33:1384-1390

8. Montgomery J, Wittwer CT, Palais R, Zhou L (2007) Simultaneous mutation scanning and genotyping by high-resolution DNA melting analysis. Nat Protoc 2:59-66

9. Yang XR, Pfeiffer RM, Wheeler W, Yeager M, Chanock S, Tucker MA et al (2009) Identification of modifier genes for cutaneous malignant melanoma in melanoma-prone families with and without CDKN2A mutations. Int J Cancer 125:2912-2917

10. Liang XS, Pfeiffer RM, Wheeler W, Maeder D, Burdette L, Yeager M et al (2012) Genetic variants in DNA repair genes and the risk of cutaneous malignant melanoma in melanoma-prone families with/without CDKN2A mutations. Int J Cancer 130:2062-2066

11. Demenais F, Mohamdi H, Chaudru V, Goldstein AM, Newton Bishop JA, Bishop DT (2010) Association of MC1R variants and host phenotypes with melanoma risk in CDKN2A mutation carriers: a GenoMEL study. J Natl Cancer Inst 102:1568-1583

12. Fargnoli MC, Gandini S, Peris K, Maisonneuve P, Raimondi S (2010) MC1R variants increase melanoma risk in families with CDKN2A mutations: a meta-analysis. Eur J Cancer 46:1413-1420

13. Wu L, Goldstein AM, Yu K, Yang XR, Rabe KG, Arslan AA et al (2014) Variants associated with susceptibility to pancreatic cancer and melanoma do not reciprocally affect risk. Cancer Epidemiol Biomarkers Prev 23(6):1121-1124
14. Yang XR, Jessop L, Myers T, Amundadottir L, Pfeiffer RM, Wheeler W et al (2011) Lack of germline PALB2 mutations in melanoma-prone families with CDKN2A mutations and pancreatic cancer. Fam Cancer 10:545-548

15. Solomon S, Das S, Brand R, Whitcomb DC (2012) Inherited pancreatic cancer syndromes. Cancer J 18:485-491

16. Talseth-Palmer BA, Wijnen JT, Andreassen EK, Barker D, JagmohanChangur S, Tops CM et al (2013) The importance of a large sample cohort for studies on modifier genes influencing disease severity in FAP patients. Hered Cancer Clin Pract 11:20

17. Lin Y, Yagyu K, Egawa N, Ueno M, Mori M, Nakao H et al (2011) An overview of genetic polymorphisms and pancreatic cancer risk in molecular epidemiologic studies. J Epidemiol 21:2-12

18. Potjer TP, Kranenburg HE, Bergman W, de Vos Tot Nederveen Cappel WH, van Monsjou HS, Barge-Schaapveld DQ et al (2015) Prospective risk of cancer and the influence of tobacco use in carriers of the p16-Leiden germline variant. Eur J Hum Genet 23(5):711-714

19. Helgadottir $\mathrm{H}$, Hoiom $V_{\text {, Jonsson }}$, , Tuominen $\mathrm{R}$, Ingvar $\mathrm{C}$, Borg A et al (2014) High risk of tobacco-related cancers in CDKN2A mutation-positive melanoma families. J Med Genet 51:545-552

\section{Submit your next manuscript to BioMed Central and take full advantage of:}

- Convenient online submission

- Thorough peer review

- No space constraints or color figure charges

- Immediate publication on acceptance

- Inclusion in PubMed, CAS, Scopus and Google Scholar

- Research which is freely available for redistribution

Submit your manuscript at

www.biomedcentral.com/submit

() BioMed Central 